Birlesik Dünya Arastırma

BD-CENTER

Innovasyon ve Yayınıılık Merkezi

\section{Global Journal of Foreign \\ Language Teaching}

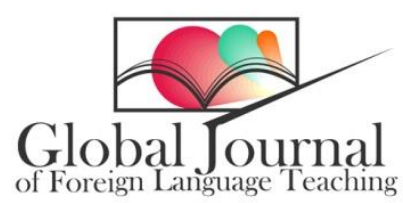

Volume 11, Issue 2, (2021) 80-93

www.gjflt.eu

\title{
Facebook as a learning platform in Algeria during the COVID-19 pandemic
}

Nadia Ghounane*, Moulay Tahar University, Department of English Language and Literature, Saida 20000, Algeria

\section{Suggested Citation:}

Ghounane, N. (2021). Facebook as a learning platform in Algeria during the COVID-19 pandemic. Global Journal of Foreign Language Teaching. 11(2), 80-93. https://doi.org/10.18844/giflt.v11i2.5555

Received from November 14, 2020; revised from February 3, 2021; accepted from May 18, 2021.

Selection and peer review under responsibility of Assoc. Prof. Dr. Jesus Garcia Laborda, Alcala University, Spain. (C)2021 Birlesik Dunya Yenilik Arastirma ve Yayincilik Merkezi. All rights reserved.

\section{Abstract}

With the dawn of high-tech phone applications and the constant spread of internet uses, social media networking sites have become a refuge for billions of users. Facebook is the leading social media tool and this research work aims to project light into the teaching/learning situation in the Algerian context, mainly the teaching of the English Language. A total of 80 Master's students and 10 teachers from the Department of English Language and Literature at Saida were used as a case study. This is to provide an inkling on the most employed social platform in the teaching and learning process during the absence of face-to-face interaction. The research tools were mainly a questionnaire, an interview and a post-test assessment. From our results, Facebook was the second leading e-learning tool after Moodle platform during the pandemic. The paper recommends some strategies on how Facebook can be employed effectively in the teaching and learning process after the pandemic.

Keywords: COVID-19 pandemic, educational platforms, EFL learners, Facebook, higher education.

* ADDRESS FOR CORRESPONDENCE: Nadia Ghounane, Department of English Language and Literature, Moulay Tahar University, Saida 20000, Algeria.

E-mail address: nadoushben@ymail.com 


\section{Introduction}

Human relationships and daily communication have significantly changed during the last few decades due to the dawn of technology. People are able to do business through applications, software and email messaging. Hence, technology has turned the entire world into a small village where people are not obliged to travel to do business. This fact makes people heavy users of technology, especially with the birth of new applications and software. The field of education is no exception. Many educators and scholars believe that technology will shape the way people communicate, do business and learn. Technology has taken a spindle role in the last few years since both teachers and students believe that technology can create an appropriate atmosphere for the learning and teaching process.

With the dawn of network technologies which have become the core of all humans' daily lives, entertainment and learning, almost all children, teenagers and adults have turned into tech addicts. Children start learning how to use these technologies at an early age. For Prenskt (2001), technology has become an integral component in the learning process since most of the students are digital natives (as cited in Barczyk \& Duncan, 2013).

The learning process has constantly changed with the rapid development of these new technologies and can be carried out directly through face-to-face interactions or virtually through the help of many applications and social media systems. Some studies have found that students are familiar with the use of social media in communication and learning more than the new emerging applications and educational platforms. In this regard, Dermott (2013) argued that children and teenagers as 'digital natives grow up and are surrounded by technology and become accustomed to using new media throughout their daily lives' (as cited in Albantani, Madkur \& Rozak, 2018, p. 1).

The deep impact of the new technologies, mainly the use of social networking sites (SNSs), has changed the way students learn. This fact has triggered scholars and educators' attention on the appropriate strategies that they can employ and how students can benefit from SNSs in learning. Facebook is among the social networking systems that has gained fame in use among people worldwide. When it comes to education, teachers and educators search for a solution to integrate SNSs, mainly Facebook, in the learning process. Although few scholarly investigations have been conducted on the use of Facebook in EFL teaching and learning, it has become the refuge of many academic institutions and universities in the last years.

Recent studies have proved that students are more motivated towards the use of SNSs in education more than the new Learning Management System (LMS) such as Moodle, blackboard, Nearpod, Kahoot and H5P. In their study, Jumaat and Tasir (2016) highlighted that SNSs 'offers opportunities for users to communicate and socialise within their bounded network' (para. 5). They also added that these services like Facebook have 'also attracted educators to use it as a platform for academicrelated discussion and in delivering online courses' (para. 5).

With regard to the studies that explored how to integrate Facebook in the teaching/learning process are concerned, most research works focused on the students and teachers' attitudes, students' motivation and which type of activities should be posted online. Although researchers were interested in how to employ Facebook as an educational platform, most of the previous studies gave importance to details on face-to-face interactions and classroom environment (Lam, 2012).

Education has witnessed immense changes during the COVID-19 pandemic and the online teaching/learning process has become the only refuge for most institutions and universities worldwide. Algeria, like many other countries, strives to promote learning for students during the pandemic using educational platforms such as Moodle and Teams. Teachers also employ other substitutions to replace face-to-face interactions like YouTube, Zoom, Google Meet and SNSs, mainly Facebook. In this vein, the current research work under scrutiny aims to shed light on the teaching of the English language in Algerian universities, mainly in Saida University during the COVID-19 pandemic. It also attempts to explore the teaching/learning situation during the pandemic. It 
endeavours to shed light on the educational procedures taken by the Department of English Language and Literature at Saida University during the pandemic. The department has used both informal and formal settings in the learning process. Most of the teachers posted their lectures and activities through the Moodle platform. They also used Facebook in the learning process. In this regard, the main question is: Did Facebook help EFL students at Saida University during the COVID-19 pandemic? In this sense, the following research questions pilot the study:

- Did teachers use Facebook as a learning platform during the pandemic?

- Did the use of Facebook meet the students' needs?

- How did both teachers and students view the use of Facebook during the pandemic?

\section{Literature review}

\subsection{Social networking sites and English language learning}

SNSs have recently received researchers' attention on how they can be integrated into the learning process. With regard to the use of SNSs in learning, some researchers, such as Arnold and Paulus (2020) and DeAndrea et al. (2011), have observed that people can employ them to strengthen social interactions and foster communications through sharing knowledge in their group (as cited in Almarwaey, 2017). Other researchers have concentrated on using SNSs to improve the students' motivation in learning English.

It is important to make a distinction between social media and social network sites. Carr and Hayes $(2015$, p. 51$)$ claimed that social media tools are part of social media. They added that 'not all social media are inherently social network sites' (as cited in Alnujaida, 2017, p. 35). Another distinction between social media and SNSs is that the former stresses the importance of making new relationships, mainly between strangers, while the latter gives importance to strengthen communication between individuals of the same group.

Among the most popular SNSs, which are employed worldwide, Facebook has taken the leading position. According to Alnujaida (2017), statistics has put Facebook at the first ranking position, followed by YouTube and Twitter, as shown in Figure 1.

\begin{tabular}{lcccccc}
\hline \multicolumn{1}{c}{ SNS } & $\begin{array}{c}\text { Monthly } \\
\text { Visitors }\end{array}$ & $\begin{array}{c}\text { eBizMBA } \\
\text { Rank }\end{array}$ & $\begin{array}{c}\text { Compete } \\
\text { Rank }\end{array}$ & $\begin{array}{c}\text { Quantcast } \\
\text { Rank }\end{array}$ & $\begin{array}{c}\text { Alexa } \\
\text { Rank }\end{array}$ & Total Rank \\
\hline Facebook & 1.100 .000 .000 & 3 & 3 & 3 & 2 & 1 \\
\hline YouTube & 1.000 .000 .000 & 3 & 4 & 2 & 3 & 2 \\
\hline Twitter & 310.000 .000 & 12 & 21 & 8 & 8 & 3 \\
\hline LinkedIn & 255.000 .000 & 18 & 25 & 19 & 9 & 4 \\
\hline Pinterest & 250.000 .000 & 22 & 27 & 13 & 26 & 5 \\
\hline Google Plus + & 120.000 .000 & 30 & 32 & 28 & NA & 6 \\
\hline Tumblr & 110.000 .000 & 34 & 55 & 13 & 34 & 7 \\
\hline Instagram & 100.000 .000 & 77 & 49 & 145 & 36 & 8 \\
\hline Reddit & 85.000 .000 & 85 & 81 & 146 & 30 & 9 \\
\hline VK & 80.000 .000 & 97 & 150 & 120 & 21 & 10 \\
\hline Flickr & 56.000 .000 & 123 & 138 & 139 & 91 & 11 \\
\hline Vine & 42.000 .000 & 581 & 237 & 335 & 1172 & 12 \\
\hline Meetup & 40.000 .000 & 596 & 791 & 701 & 296 & 13 \\
\hline Ask.fm & 37.000 .000 & 779 & 2046 & 113 & 179 & 14 \\
\hline Classmates & 15.000 .000 & 1487 & 153 & 285 & 4022 & 15 \\
\hline
\end{tabular}

Figure 1. The most leading social network sites worldwide (Adapted from Alnujaida, 2017, p. 35) 
With regard to the use of SNSs in the EFL context, many studies have revealed that the learning process has become more social. In their study, Carmean and Harfner (2002) maintained that the application of social networks makes the second language learning more social and enjoyable with minimal stress' (as cited in Derakhshan \& Hasanabbasi, 2015, p. 1091). Learning can be socially directed and henceforth has turned from teacher-centred to learner-centred. Through the joining groups, students can share information and learn from each other. Through discussions in online communication, students can get feedback from each other. In the same line of thought, Bicen, Sadikoglu and Sadikoglu (2015) pinpointed that the increased use of SNSs, mainly Facebook and Twitter, leads students to share and benefit from each other. Hence, SNS users can benefit from the use of these sites to enjoy the learning process since they provide a variety of learning tools including audio and video materials.

Most studies, which are conducted on the use of SNSs in learning English, are focused on the effectiveness of these sites in changing the learning environment, while later studies gave more importance to the skills that can be improved through SNSs, mainly Facebook. A study conducted by Ofugi and Olievira (2010) proved that Facebook, as the most leading SNSs tool, can help students to improve their writing skills in the English language (Khoshnoud \& Karbalaei, 2014). Other researchers were interested in how to change the learning process from a formal to an informal setting. Although the purpose and the findings of these studies differ largely, these research works share that universities and institutions can utilise Facebook as a teaching and learning tool that can change the learning environment and make it more enjoyable, communicative and competitive. Therefore, this may improve the learning process.

\subsection{Facebook in teaching and learning}

Facebook has become, in the last few years, the refuge of young and old people in all domains. Education has made no exception since pupils and students start creating groups to share and benefit from the information shared in the groups. Hence, most institutions and academics turn their attention to the possibility of integrating this platform into the learning and teaching process. To achieve this aim, a bunch of scholarly investigations has turned their attention towards the possibility of exploring the benefit of Facebook in an academic setting.

Most of the referent studies have explored the possible ways to employ Facebook as an educational platform, mainly in the EFL context. Some of these studies have proposed some steps and strategies to integrate Facebook into the learning process. A good example of these studies is the one conducted by Phillips et al. (2011). This study gives an overview of how to use groups on Facebook for educational purposes, while other studies tend to investigate the importance of creating and using groups in communication through the use of language. In this regard, Blattner and Fiori (2009) pinpointed that 'the value of using of groups, emphasising the benefits of real language interaction and development of social-pragmatic knowledge that is often missing in the textbooks' (as cited in Rojas-Kramer, Esquivel-Gamez, \& Garcia-Santillan, 2015, p. 4).

To make the learning process more enjoyable and successful through Facebook, researchers tend to explore the possibility of using what is called the Facebook-based learning platform. In their study, Li et al. (2013) tended to 'integrate Facebook-based learning platform with blended learning model and flip learning strategies' (Dweikat, 2016, p. 2293). This study shows that the platform helped learners to enjoy flip learning in comparison to the traditional way of teaching.

Early studies, like those of Miyasone (2007), gave more importance to exploring the relationship between Facebook and cooperative learning. In his study, Dweikat (2016, p. 2296) claimed that 'Facebook-integrated blended learning approach can assist students' English learning organisation, grammar, and structure, content, vocabulary and spelling'. He added that Miyasone's study revealed that the icon of like helps to raise the students' motivation to learn English. 
As far as learning writing is concerned, some studies have proved the effectiveness of Facebook in improving writing skills. In their study, Melor et al. (2012) highlighted that students can learn vocabulary through reading the comments of each other. They also proved that 'using Facebook actually can help the students in completing their essays easier by participating in the Facebook group discussion' (as cited in Ghani, 2015, p. 98).

Facebook brings three main points that can make it the first SNSs to be used for educational purposes. In their study, Mazman and Usluel (2010) posited that three functions can help in using Facebook as an educational platform (Wang \& Chen, 2013). These functions are limited to communication, collaboration and material sharing. Mazman and Usluel (2010) explained that:

Communication consists of activities such as enabling communication among students and their instructors, facilitating class discussions, delivery of homework and assignments by teachers, informing about resources and links related to courses; consist of activities such as people's joining academic groups related to their schools, departments or classes and carrying on group works by sharing homework, projects, and ideas; collaboration consists of activities such as exchanging multimedia resources, videos, audio materials, animated videos, resources and documents (Wang \& Chen, 2013, p. 136).

Hence, most of the conducted studies have focused on the effectiveness of Facebook as an educational platform where teachers and students can meet virtually; however, few studies were conducted on the appropriate strategies that can be employed to make Facebook a useful platform.

\subsection{Teaching and learning of English during the COVID-19 pandemic}

As the COVID-19 pandemic runs worldwide, all fields in all countries have locked down and governments are striving to implement strategies and measures to limit people's contact in public spaces. Education has made no exception. The pandemic deeply affects the learning process in schools and universities. Hence, the ministries of education strive to promote learning through different platforms to continue the learning process until they find solutions for the current situation.

Although most countries provide measures for online learning, there are still some hindrances that disrupt the learning process, mainly in countries that do not have developed systems for online learning. Among the constraints, which face virtual learning, are technical problems. Indeed, not all students have access to the net or have computers or mobile phones. Another reason is that most of the learners and some teachers have low background knowledge in using information and communication technology (ICT). Therefore, some teachers have developed what is called tech resistance to the use of $\mathrm{ICT}$, even though some of them have mastered the use of the Internet. Besides, other teachers have developed a technophobia to the use of ICT in class. All these constraints make virtual learning impossible in some countries. On the other hand, some countries find no difficulties in virtual learning since they have already integrated that into the learning process. In light of these ideas, Schleicher (2020, p. 4) posited that:

Although higher education institutions were quick to replace face-to-face lectures with online learning, these closures affected learning and examinations as well as the safety and legal status of international students in their host country. Perhaps most importantly, the crisis raises questions about the value offered by a university education which includes networking and social opportunities as well as educational content. To remain relevant, universities will need to reinvent their learning environments so that digitalisation expands and complements student-teacher and other relationships.

To solve the problem, universities tend to use platforms like Moodle and blackboard. They also search for other substitutions like Google Meet, Zoom and Team applications. Therefore, they tend to employ formal ways to promote learning. SNSs also have a lion's share in the learning process during the pandemic, mainly Facebook and YouTube. Although these platforms are seen as informal ways for 
academic institutions and universities, most of them depend on their use, mainly for administrative purposes. Facebook provides an informal setting for teachers and students to meet. Teachers tend to share their lectures through this platform.

Many researchers conducted their studies online during the pandemic. Some of the studies explored students' readiness to study online. In their study, Ergun and Adibatmaz (2020) claimed that the lockdown obliged both institutions and students to switch to e-learning, although there are many difficulties, such as students' readiness, infrastructure and lack of tech materials. Besides, institutions also have to take into consideration other social and economic factors that also prevent students from joining e-learning options during the pandemic. In their study, Ajayi and Ajayi (2020) saw that these difficulties do not prevent students from enjoying the new learning environment through using different platforms. At least, they tend to break down the classroom environment and home boundaries. Similarly, Lin, Fang, Hsueh and Lai (2019) opined that changing the learning mode leads students to develop their self-discovery, socialisation and diversity.

Although Facebook has taken up the lion's share in informal and formal settings, few studies were conducted on its effectiveness during the pandemic. Froilan (2020) is among the scholars who researched for solutions to meet students' needs. He created a Facebook group chat and found that Facebook can be used for teaching and learning purposes. He implemented both linear and nonlinear modelling to implement academic purposes. Another important study was conducted by Avila and Cabrera Jr (2020). The study found that the use of Facebook as a learning platform helped students to develop their academic performance. They concluded that both students and institutions should be careful in using SNSs, mainly Facebook in the teaching and learning process. In the same vein, Anggoro and Rueangrong (2021) claimed that Facebook can be used as both a learning management and a teleconferencing tool. In this regard, they wrote that:

Facebook is one of them. Facebook can act both as a Learning Management System (LMS) and a teleconferencing tool. As LMS, it can facilitate both asynchronous and synchronous communication and interaction as well as store various files related to the lessons. As a teleconferencing tool, it can facilitate a free, private, and successful real-time video meeting with students. Most importantly, as a popular social media application, many people are familiar with how to use it (para. 1).

Hence, the study found that Facebook helped in easing the interaction between teachers and students. Although many studies triggered the issue of using Facebook as a LMS, few investigations have dealt with how to use it in the learning process during the pandemic. Through the current paper, the researcher tends to study how EFL teachers at Dr. Moulay Tahar University tend to employ Facebook during the pandemic.

\section{Methods and materials}

The main aim of the study is to shed light on the use of Facebook as a learning platform during the COVID-19 pandemic. The researcher also tends to test the teachers' motivation towards the use of Facebook. The third main focus is to check whether the students are motivated to employ Facebook as a learning platform and share the group with their teachers and test the effectiveness of Facebook itself as an educational platform or not.

The researcher adopted a mixed methodology of a quantitative and qualitative approach to gather data in relation to the study's main question and research problem. Quantitative research aims to describe data, while qualitative research is more dominant in the work. All informants showed positive attitudes and interest to participate in the study.

\subsection{Instruments}

A total of 87 students were selected and invited to answer a closed-ended online questionnaire via the researcher's email. The main aim of the questionnaire was to check the students' opinions and 
views on the use of Facebook as an educational platform during the pandemic. To support the findings of the questionnaire, the researcher conducted a semi-structured interview with 10 teachers. The interview added a qualitative dimension to the findings of the questionnaire. The interview aimed to check the teachers' measures to contact the students and whether they are motivated or not to use Facebook.

The questionnaire contains 'yes' and 'no' questions to check whether the students are familiar with the use of Facebook as an educational platform before the pandemic or not. The researcher also employed Likert-type questions to test their attitudes towards sharing their groups on Facebook with their teachers during the pandemic and whether they tend to share the groups with their teachers after the pandemic or not.

The researcher taught the two groups research methodology during the academic year 2019/2020. She posted activities as a part of the students' post-test assessment during the second semester and to test their background knowledge after the lectures had been posted. Students were informed to send the answers to these activities through the researcher's email. Figure 2 shows an overview of the activities which were posted on the student's groups to assess them.

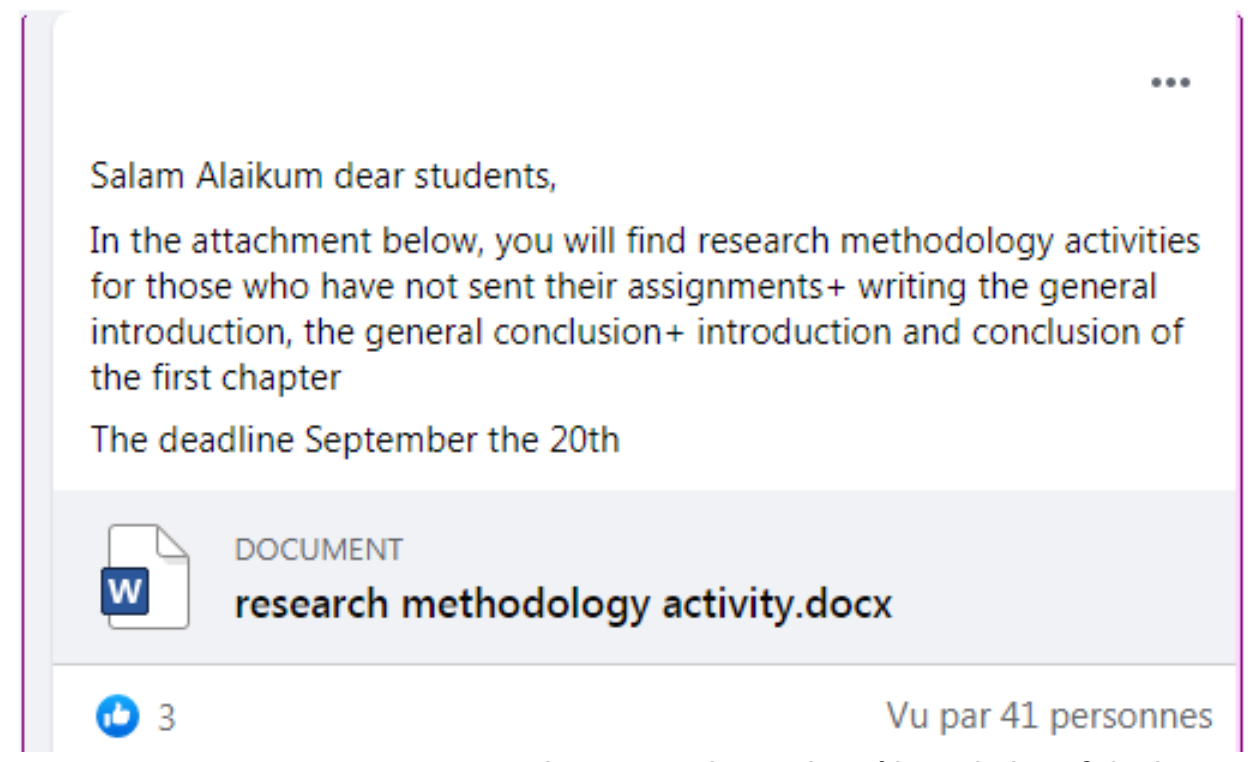

Figure 2. Post-test assessment posted to assess the students' knowledge of the lectures

\subsection{Participants}

As the researcher had already mentioned, 80 students were randomly selected. The students were studying the Master's degree from two specialties (Literature and Didactics). The study took place at the Department of English, Saida University, Algeria. These two groups created their groups on Facebook where they could share, discuss and communicate knowledge. The study was conducted during the second semester after the outbreak of the pandemic. Although the questionnaire was posted on their groups of Facebook, only 80 students answered and sent the questionnaire to the researcher's email.

\section{Findings}

\subsection{Questionnaire}

The researcher included in the presentation and analysis of the students' questionnaire the most important questions which are related to the research questions. 


\subsubsection{Students' familiarity with Facebook as an educational platform}

Table 1. Students' familiarity with Facebook as an educational platform

\begin{tabular}{lc}
\hline Familiarity & Participants' answers \\
\hline Yes & $58 \%$ \\
No & $22 \%$ \\
\hline
\end{tabular}

Table 1 shows that $58 \%$ of the participants are familiar with the use of Facebook as an educational platform and maintain that they wish that all teachers of their level can join their group. They add that they join some groups created by teachers from other universities. On the contrary, other students answered that Facebook is used by their classmates to discuss and communicate some related issues in learning in an informal setting since they resort to Arabic, French or Algerian dialectal Arabic in writing their comments. They cannot learn how to communicate or write in English through Facebook.

\subsubsection{Students' attitudes towards the use of Facebook as an educational platform to improve English learning and teaching after the pandemic}

Table 2. Students' attitudes towards the use of Facebook as an educational platform

\begin{tabular}{lc}
\hline \multicolumn{1}{c}{ Attitudes } & Participants' answers \\
\hline Strongly agree & $13 \%$ \\
Agree & $47 \%$ \\
Strongly disagree & $07 \%$ \\
Disagree & $13 \%$ \\
\hline
\end{tabular}

Table 2 reveals that $47 \%$ of the informants share positive attitudes towards the use of Facebook as an educational platform, while $13 \%$ of them strongly agree. On the contrary, $20 \%$ of the participants' answers were between strongly disagree and disagree. Indeed, they showed their uncertainty of using Facebook as an educational platform and how it can improve the learning and teaching of English.

\subsubsection{Students' reaction towards their teachers who join their group}

Table 3. Students' attitudes towards the use of Facebook as an educational platform

\begin{tabular}{lc}
\hline \multicolumn{1}{c}{ Attitudes } & Participants' answers \\
\hline Strongly agree & $13 \%$ \\
Agree & $47 \%$ \\
Strongly disagree & $07 \%$ \\
Disagree & $13 \%$ \\
\hline
\end{tabular}

Table 3 indicates that $47 \%$ of the informants are motivated to use Facebook for educational purposes, while $13 \%$ strongly agree. On the other hand, $13 \%$ of the participants strongly disagree with using Facebook as an educational platform, claiming that there are formal educational platforms imposed by the Ministry of Higher Education for learning, mainly Moodle.

\subsubsection{Students' beliefs on the use of Facebook to improve the learning process}

Table 4. Students' beliefs on the effectiveness of Facebook in learning English

\begin{tabular}{lc}
\hline Beliefs & Participants' answers \\
\hline Yes & $65 \%$ \\
No & $15 \%$ \\
\hline
\end{tabular}

Table 4 shows that $65 \%$ of the informants maintained that SNSs, in general, mainly Facebook, can improve the learning process informally since it is not an academic platform. They justified their choice maintaining that through the option 'like' they can share and provide comments. They can also discuss raised issues. On the contrary, $15 \%$ of the participants claimed that Facebook is an informal system where they can meet, share and provide comments. 


\subsubsection{Students' beliefs on Facebook as a tool to promote communication between the members of the group} Table 5. Students' beliefs on Facebook as a tool of communication in the group

\begin{tabular}{lc}
\hline Beliefs & Participants' answers \\
\hline Yes & $78 \%$ \\
No & $02 \%$ \\
\hline
\end{tabular}

Table 5 reveals that most of the students favour the use of Facebook as a tool to promote communication between class peers, while $2 \%$ of the informants claimed that they create Facebook to have an atmosphere of fun. They added that for communication with peers, they prefer to use other SNSs like WhatsApp and Twitter rather than Facebook to maintain privacy.

\subsubsection{Effectiveness of Facebook as an educational tool during the pandemic}

Table 6. The effectiveness of Facebook during the pandemic

\begin{tabular}{lc}
\hline Effectiveness & Participants' answers \\
\hline Yes & $79 \%$ \\
No & $01 \%$ \\
\hline
\end{tabular}

According to Table 6, most students reported that Facebook was the most used SNSs platform even by teachers and administration. They added that the platform is used to share lectures during the pandemic. It was also employed for administrative purposes, while just $1 \%$ of the informants responded negatively.

\subsection{Teachers' interview}

The researcher conducted a semi-structured interview with 10 teachers from the Department of English Language and Literature at Saida University. The process took 2 weeks to receive the answer to the interview. The researcher selected the most important questions for the analysis.

\subsubsection{Teachers' attitudes towards the use of Facebook as an educational platform}

Five teachers out of 10 maintained that they have positive attitudes towards the use of Facebook for educational purposes. They justified their answers that the use of Facebook cannot be restricted to announcements or posting lectures. Students and teachers can benefit from Facebook for learning through an online classroom. They also added that to motivate the students to employ Facebook as an educational platform, teachers should raise their learners' awareness of the main difference between entertainment and intellectual engagement. Two of the teachers claimed that teachers, who use Facebook for educational purposes, need to make sure that their students benefit from the activities they post on Facebook.

\subsubsection{Challenges facing teachers to use Facebook for educational purposes}

Nine teachers out of 10 maintained that most of the students tend to communicate through Algerian dialectal Arabic. Hence, they cannot learn Standard English through communication with their peers. They added that it is impossible to tell the students to use English or look after their language use since they are in an informal setting. Three teachers out of 10 informed that teachers can never meet in a group with students as friends since they are afraid to lose their privacy. They further highlighted that teachers can meet with students in a group designed by the administration for educational purposes. They further maintained that teachers have also to check students' preferences and motivation to learning, i.e., the teacher should know whether the student is motivated to learn through Facebook or prefers the traditional way of learning. 


\subsubsection{Teachers' use of Facebook before the pandemic}

Six out of 10 teachers answered that they used Facebook but not as an educational platform. They added that they profit from the platform to announce activities for absent students. It is also employed to share lectures and books for further readings.

\subsubsection{Teachers' use of Facebook during the pandemic}

All the teachers responded that they employed Facebook during the pandemic to support the Moodle platform. They added that they posted lectures on both Moodle and Facebook to provide the possibility for all students to share lectures. They also claimed that most of the use of Facebook was for administrative purposes through the department's Facebook. Hence, Facebook is considered a supplementary tool to promote lectures and announcements for all students.

\subsubsection{Did Facebook meet the students' needs during the pandemic?}

All the teachers answered that Facebook cannot meet the students' needs as an educational platform since no application or platform can replace classroom environment and face-to-face interaction, although some teachers provide supplementary materials as videos that provide explanations of the lecture. They insisted on the learning environment as an important component in the teaching and learning process.

\subsection{Post-test assessment}

The researcher posted the lectures on Facebook between March and May. Most of these lectures were published on YouTube. Students were just provided with the link to the lectures on Facebook. These videos were supported by activities as a part of a post-test assessment to test their background knowledge as shown in Figure 2. The researcher also engaged with her students on an online discussion every week by the end of May to answer the students' questions about the lectures. Figure 3 shows an overview of one of the lectures which was published on YouTube and posted on Facebook.

\section{Master 1 civ and lit Students}

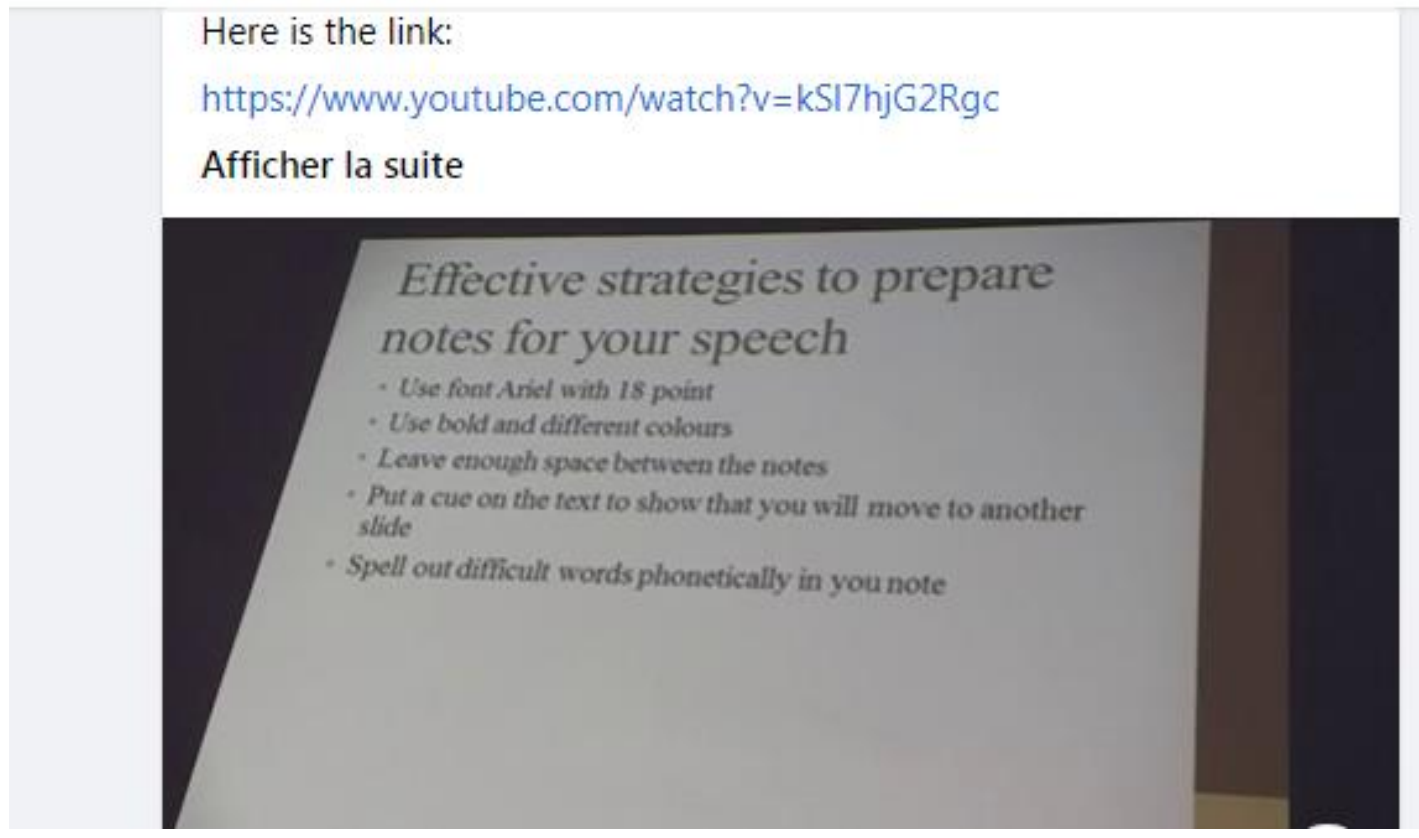

Figure 3. Links on YouTube prepared by the researcher and posted on Facebook 
The post-test assessment contained questions from all the lectures published on YouTube and then published on Facebook. The lectures tackled how to write the literature review section, types of paragraphs in academic writing, types of claims that build an argument and types of literature reviews. The collected data, which were taken from the post-test, were corrected and analysed by the teacher, as shown in Table 7.

Table 7. Students' level after the post-test assessment

\begin{tabular}{lcc}
\hline \multicolumn{1}{c}{ Specialties } & Students' number & Score \\
\hline Literature and civilisation & 40 & $15.5 \%$ \\
didactics & 40 & $17.5 \%$ \\
\hline
\end{tabular}

Table 7 shows that $15.5 \%$ out of 40 students, who are specialised in literature and civilisation, answered most of the questions of the post-test assessment. Similarly, $17.5 \%$ of the students, who are specialised in didactics, answered the questions and got an average.

The results of the post-test assessment also demonstrated that most of the students engaged in learning, online discussions and answering activities. They were also curious about the results of the post-test assessment since it was a part of their semester marks.

As far as the research methodology module is concerned, the results show that the students performed better in distinguishing the different types of paragraphs, mainly the PEE and PEEL paragraphs which are used to write the literature review section. The results also reveal that students built background knowledge on how the differentiate the types of evidence and how to place it within the PEE and PEEL paragraphs. The students also learned different types of literature reviews and organisations, mainly the methodological and thematic organisations.

\section{Discussion}

The overall results of the current study under scrutiny aim to provide an inkling into the teachers and students' motivation towards the use of Facebook as an educational platform during the COVID19 pandemic. The findings reveal that most students share positive attitudes towards the use of Facebook as a social and educational platform. This is in line with Kirschner and Kaspinski's (2010) study. The findings also demonstrate that both teachers and students have to use Facebook effectively, i.e., learners have to make a distinction between entertainment and learning through the platform, while teachers need to search for the appropriate strategies so that the use of Facebook can meet their learners' needs. This is the answer to the second question 'Did the use of Facebook meet the students' needs?

The analysis also reveals that teachers employ Facebook during the pandemic as a supplementary tool since the department uses Moodle as a formal educational platform. Teachers utilise Facebook through creating writing workshops for first- and second-year students and additional sources like videos and e-books through 'book tag' to improve their understanding of the lectures. Therefore, it boosts confidence and develops the relationship between the instructors and the students for its future use, although teachers' supervision and guidance are always needed in the learning process. This finding is in line with Ajayi and Ajayi's (2020) study, which found that Facebook promotes socialisation between students and their teachers. Lin et al. (2020) shared the same view that Facebook can be used as a shared learning platform and can change the learning process from a teacher-centred into a learner-centred approach. This may answer the first research question 'Did teachers use Facebook as a learning platform during the pandemic?'

The findings also demonstrate that students and teachers find Facebook as a refuge for direct meetings where it can provide an appropriate virtual learning environment during the pandemic. The analysis reveals that students shared more academic sources and learning materials during the pandemic. Under close investigation, the researcher confirmed that learners used their groups on Facebook more for academic purposes rather than for entertainment during the pandemic. The 
researcher came across the point that the pandemic has helped students to develop their interpersonal collaboration and peer support through the use of Facebook, on one hand, and changes teachers' views and motivation towards SNSs, in general, on the other. This finding is in line with Ganapathy, Kabilan and Meenakshisundram's (2020) research. They believed that learning during the pandemic using social learning environments was more useful in comparison to other educational systems. This may answer the third research question 'How did both teachers and students view the use of Facebook during the pandemic?'

Although it was difficult to manage the learning process through Facebook due to the absence of face-to-face interaction, the results show that the students' attitudes towards the use of SNSs as learning platforms have changed. The use of Facebook and the students' engagement in short online discussions can promote blended and flipped learning, unlike the traditional classroom.

As far as academic writing and research methodology are concerned, the findings of this study are consistent with those of Ibrahim (2013) Ofugi and Olievira (2010), who claimed Facebook can improve the students' writing skills. Through the selected activities for the post-test assessment, the researcher recognised that posting videos rather than hand outs or books are more useful to motivate learners in the writing process.

\section{Conclusion}

The current research work is designed to explore the teaching situation of English for EFL learners at Saida University and the effectiveness of Facebook as an educational platform during the COVID-19 pandemic. The focal aim of the paper is to put the teaching/ learning situation under the lens and show the effectiveness of SNSs tools, mainly Facebook, during this period. The findings of the study prove that teachers and students benefited from Facebook as a learning platform during the pandemic through enlarging its usage to include communication and collaboration to share knowledge and experiences where teachers should play the role of dominance in leading the learning process.

Technology and its tools have become an integral part of individuals' daily lives. Education, as other important fields, has put technology as its first concern to develop the learning process. Hence, teachers and students have to cope with any advances in the field of technology. Although teachers show resistance towards the use of social media in classrooms, mainly Facebook, their attitudes have changed during the pandemic. Educators have to check the main challenges and pitfalls during their planning. Therefore, the COVID-19 pandemic puts the use of technology in higher education under the lens where instructors and educators struggle to find solutions to replace face-to-face learning and classroom environment after the outbreak.

\section{Limitations and recommendations}

Although this study comprises a small number of informants, it can offer a roadmap for future researchers to find solutions to employ SNSs, in general, and Facebook, in particular, to promote learning, mainly during the pandemic rather than restricting its use to administrative purposes. Hence, the research draws important notes, amazing fresh ideas and recommendations that would optimistically - install curiosity and confidence in aspiring EFL teachers and students alike towards the use of SNSs in learning. Driven by this ambition, the researcher recommended future studies on the use of SNSs. Therefore, she provided the following recommended points:

- Teachers can guide their students with the proper use of Facebook by raising their awareness of the applications that can enhance the learning process. Among these applications, there is 'Flashcarflet' which helps students to develop their vocabulary, while 'Knighthood' is another application that can improve their reading skills. 
- Teachers should show learners that Facebook does not only facilitate and promote interaction but can provide authentic interaction and help them to share materials and new experiences in learning the English Language.

- Teachers should care about their students' learning preferences and provide the appropriate mode of teaching to fit their needs.

- Teachers can turn Facebook from student-to-student into teachers-to-students interaction by creating teachers' groups that help teachers to hold the dominant position.

- Teachers should direct the role of their designed groups from distributing materials and announcements to providing a space for learning and exchanging knowledge.

- Teachers and administrations should take into account solving all the difficulties facing students in using Facebook as a learning platform. Hence, findings solutions for these constraints may help in promoting an asynchronous learning environment that can support developing the students' cognitive abilities, as Lizzo and Liechty (2020) stated in their study.

Therefore, the last line of this research is an eloquently aspirational appeal to future researchers, coming with that eagerness in the field, to surpass the side effects and the constraints of this study.

\section{References}

Ajayi, P. O. \& Ajayi, L. F. (2020). Use of online collaborative learning strategy in enhancing postgraduates learning outcomes in science education. Educational Research and Reviews, 15(8), 504-510. doi: 10.5897/ ERR2020.4023

Albantani, A. M., Madkur, A. \& Rozak, A. (2018, October 2-4). Social media in the classroom: the use of Facebook in foreign language learning. Proceedings of the 2nd International Conference on Quran and Hadith Studies Information Technology and Media in Conjunction with the 1st International Conference on Islam, Science and Technology, ICONQUHAS \& ICONIST, Bandung. Indonesia: EAI. doi:10.4108/eai.2-102018.2295511

Almarwaey, A. O. (2017). Using social-networking sites in learning English language and students' self-efficacy. US-China Education Review, 7(5), 346-454. doi:10.17265/2161-623X/2017.05.003

Alnujaida, S. (2017). Social network sites as ESL/EFL learning and teaching tools: a critical review. International Journal of Applied Linguistics and English Literature, 6(3), 34-42. doi:10.7575/aiac.ijalel.v.6n.3p.34

Anggoro, K. J. \& Rueangrong, P. (2021). Facebook: an alternative learning platform for online English as a foreign language instruction in the time of COVID-19. Journal of Education Naresuan University, 23(1), 413-423.

Avila, E. C. \& Cabrera Jr, H. I. (2020). The use of Facebook group in distance learning during the time of COVID-19 pandemic. Scientific Journals in Palaeontology and Egyptology, 17(6), 1859-1871.

Barczyk, C. C. \& Duncan, D. G. (2011). Social networking media as a tool for teaching business administration courses. International Journal of Humanities and Social Sciences, 1(17), 267-276.

Barczyk, C. C. \& Duncan, D. G. (2013). Facebook in higher education courses: an analysis of students' attitudes, community of practice, and classroom community. International Business and Management, 6(1), 1-11. doi:10.3968/j.ibm.1923842820130601.1165

Bicen, H., Sadikoglu, S. \& Sadikoglu, G. (2015). The Impact of Social Networks on Undergraduate Students Learning Foreign Language. 5th World Conference Networks on Undergraduate Students Learning Foreign Language. Procedia - Social and Behavioral Sciences, 186, 1045-1049.

Derakhshan, A. \& Hasanabbasi, S. (2015). Social networks for language learning. Theory and Practice in Language Studies, 5(5), 1090-1095. doi:10.17507/tpls.0505.25 
Dweikat, K. (2016). Impact of using Facebook on improving English communication skills- the case of implementing the English language course as a model at Al-Quds Open University. An-Najah University Journal for Research-B (Humanities), 30(11), 2287-2318.

Froilan, M. D. (2020). Using Facebook social media amidst COVID-19 as an e-learning platform. Universe International Journal of Interdisciplinary Research, 1(2). Retrieved from https://papers.ssrn.com/sol3/ papers.cfm?abstract_id=3668724

Ganapathy, M., Kabilan, M. K. \& Meenakshisundram, S. D. (2020). English language teachers' practices of online professional development using Facebook. Pertanika Journal of Social Science \& Humanities, 28(1), 251-266.

Ghani, M. B. (2015). Using Facebook in teaching and learning English. The International Conference on Language, Literature, Culture and Education, 97-102. Retrieved from https://icsai.org/procarch/2icllce/2icllce92.pdf

Ibrahim, M. G. (2013). The effect of using Facebook on improving students' writing skills in English (Unpublished Master's Thesis). AnNajah National University, Nablus, Palestine.

Jumaat, N. F. \& Tasir, Z. (2016, May 25-27). Facebook as a platform for academic-related discussion and its impact on students success. Fourth International Conference on Information and Communication Technologies, Bandung. Indonesia: IEEE. Retrieved from Facebook_as_a_platform_for_academicrelated_discus.pdf

Khoshnoud, K. \& Karbalaei, A. (2014). The effect of interaction through social networks sites on learning English in Iranian EFL context. Journal of Advances in English Language Teaching, 2(2), 27-33.

Kirschner, P. \& Karpinski, A. (2010). Facebook for academic purposes. Computers in Human Behavior, 26(6), 1237-1245.

Lam, L. (2012). An innovative research on the usage of Facebook in the higher education context of Hong Kong. The Electronic Journal of e-Learning, 10(4), 377-386.

Lin, T. C., Fang, D., Hsueh, S. Y. \& Lai, M. C. (2019). Drivers of participation in Facebook long-term care groups: applying the use and gratification theory, social identification theory, and the modulating role of group diversity. Health Informatics Journal, 26(365), 513-527. doi:10.1177/1460458219839618

Lizzo, R. \& Liechty, T. (2020). The Hogwarts Running Club and sense of community: a netnography of a virtual community. Leisure Sciences: An Interdisciplinary Journal, 1-18. doi:10.1080/01490400.2020.1755751

Rojas-Kramer, C., Esquivel-Gamez, I. \& Garcia-Santillan, A. (2015). Educational use of Facebook in higher education environments: current practices and guidelines. Proceedings of 9th International Technology, Education and Development Conference, Madrid: Spain. pp. 6042-6052.

Schleicher, A. (2020). The impact of COVID-19 on education: insights from education at a glance 2020. Retrieved from https://www.oecd.org/education/the-impact-of-covid-19-on-education-insightseducation-at-a-glance-2020.pdf

Wang, C. \& Chen, C. (2013). Effects of Facebook tutoring on learning English as a second language. IADIS International e-Learning, 135-142. 